\title{
Lower immunity to tetanus in cigarette smoker subjects
}

\author{
Jafarzadeh A, PhD ${ }^{1}$, Shabani Z, MD ${ }^{2 *}$, Hassanabadi M, BSc ${ }^{3}$, Rezayati MT, BS ${ }^{4}$, Nemati M, BS 5 , \\ Sayadi AR, MSc ${ }^{6}$, Sheikhi A, $\mathrm{PhD}^{7}$, Vazirinejad R, $\mathrm{PhD}^{8}$ \\ 1- Professor, Molecular Medicine Research Center, Rafsanjan University of Medical Sciences, Rafsanjan, Iran. \\ 2- Assistant Prof., Immunology of Infectious Diseases Research Center, Rafsanjan University of Medical Sciences, \\ Rafsanjan, Iran. 3- Student in Molecular Medicine Research Center, Rafsanjan University of Medical Sciences, \\ Rafsanjan, Iran. 4-BSc, Molecular Medicine Research Center, Rafsanjan University of Medical Sciences, Rafsanjan, \\ Iran. 5- BSc, Dept. of Microbiology and Immunology, Medical of School, Kerman University of Medical Sciences, \\ Kerman, Iran. 6- Faculty Member, Social Determinants of Health Research Center, Rafsanjan University of Medical \\ Sciences, Rafsanjan, Iran. 7- Associate Prof., Dept. of Immunology, Medical of School, Dezful University of Medical \\ Sciences, Dezful, Iran. 8- Professor, Social Determinants of Health Research Center, Rafsanjan University of Medical \\ Sciences, Rafsanjan, Iran.
}

\begin{abstract}
Received: February 2013, Accepted: October 2013

Background: Cigarette smoking has been linked with the suppression of immune responses and increased susceptibility to numerous infections in humans. Tetanus is also a major public health problem in many countries. The aim of the present study was to evaluate the serum levels of antitetanus toxin antibodies in cigarette smoking and healthy non-smoking people.

Materials and Methods: A total of 100 cigarette smokers and 100 age-matched healthy nonsmoker individuals were enrolled in this descriptive study. A blood sample was collected from each participant. The samples were tested for the levels of anti-tetanus toxin antibodies by use of enzyme linked immunosorbent assay.

Results: The seroprotective rate of anti-tetanus toxin antibodies in non-smoking group (99\%) was significantly higher than that observed in cigarette smoking group $(78 \%, \mathrm{P}<0.0001)$. The mean titer of anti-tetanus toxin antibodies in non-smoking group $(5.32 \pm 0.26 \mathrm{IU} / \mathrm{ml})$ was also significantly higher than that in smoker subjects $(1.03 \pm 0.16 \mathrm{IU} / \mathrm{ml} ; \mathrm{P}<0.0001)$. The mean titer of anti-tetanus toxin antibodies in individuals with smoking duration $>10$ years was significantly lower than that among smokers with smoking duration $\leq 10$ years $(0.59 \pm 0.12 \mathrm{IU} / \mathrm{ml}$ vs $1.98 \pm 0.41 \mathrm{IU} / \mathrm{ml}$; $\mathrm{P}<0.001)$. The seroprotection rate was also significantly lower in persons with smoking duration $>10$ years in comparison to smokers with smoking duration $\leq 10$ years $(72.1 \%$ vs $90.6 \% ; \mathrm{P}=0.037)$. The mean titer of anti-tetanus toxin antibodies in individuals with daily smoking $>10$ cigarettes was also significantly lower in comparison to smokers with daily smoking $\leq 10$ cigarettes $(0.68 \pm$ $0.15 \mathrm{IU} / \mathrm{ml}$ vs $1.63 \pm 0.36 \mathrm{IU} / \mathrm{ml} ; \mathrm{P}<0.001)$.

Conclusion: These results showed lower levels of anti-tetanus toxin antibodies in cigarette smokers which represents cigarette smoking as a risk factor for susceptibility to tetanus. A negative association was also observed between the immunity to tetanus and smoking burden.
\end{abstract}

Keywords: Immunity, Tetanus, Antibody, Cigar Smoking

\section{Introduction}

Nowadays, about 1.25 billion people are known to be smokers worldwide and approximately 5 million death save attributed to smoking each year [1]. It has been reported that cigarette smoke consists of about 4000 substances known to be antigenic, cytotoxic, mutagenic, and carcinogenic influencing various human body organs both locally and systemic ally [2]. Both arms of immune system including

\footnotetext{
* Corresponding author: Ziba Shabani, Immunology of Infectious Diseases Research Center, Rafsanjan University of Medical, Rafsanjan, Iran.

Email: shabaniz20@yahoo.com
} 
innate and adaptive responses also were affected by cigarette smoking [3]. Therefore, cigarette smoking influences cell mediated and antibody mediated immune responses $[2,3]$. The principle function of the immune system is defense against infections and killing of tumor cells [4,5].

Accordingly, cigarette smoking was considered as a significant risk factor for cancers as well as infections [6,7]. Tetanus is an infectious disease caused by neurotoxin secreted from the gram-positive anaerobic bacillus Clostridium (C) tetani. Despite being preventable with an effective vaccine, tetanus remains a significant cause of morbidity and mortality worldwide [8]. Contamination of a wound with spores of $\mathrm{C}$. tetani usually causes tetanus, due to release of neurotoxin. Tetanus is rare in people with history of complete vaccination course. However, inadequate tetanus toxoid vaccination and wound prophylaxis are associated with tetanus. Risks of fatal disease is also reported to be higher in patients 60 years of age and older $[9,10]$. The current recommendation of Advisory Committee on Immunization Practices and Centers for Disease Control and Prevention is to administrate the diphtheria, tetanus, and acellular pertussis vaccine (DTaP) at ages 2, 4, 6, 15-18 months with a booster at 4-6 years [8]. In Iran, immunization against diphtheria, tetanus and pertussis has been applied since 1950 using a local vaccine manufactured by Razi Institute (Razi-DTwP) [11,12]. In most countries, booster immunization of diphtheria and tetanus is recommended to be performed every 10 years. Booster tetanus-diphtheria (Td) vaccine is recommended to start at the age of 11-12 years old [13].

Cigarette smoking has local and systemic effects on the immune system and increases the susceptibility to infections and also alter the course of infectious diseases [6]. The results of some studies also demonstrated that smoking impairs the antibody response to infectious agents such as viruses and bacteria [14]. Moreover, lower antibody responses to some vaccines have been reported in smokers in comparison to nonsmokers [15]. Furthermore, cigarette smoking is associated with delay in wound healing such as skin wounds [16,17]. Accordingly, it is expectable that cigarette smokers may be at a higher risk for tetanus than non-smoker subjects. This study conducted for the first time to evaluate the serum levels of anti-TTA in cigarette smoker subjects and in a healthy non-smoking group.

\section{Material and Methods}

This descriptive study was carried out in Rafsanjan (a city that located in South-East of Iran in Kerman province) From January 2012 to June 2012. One hundred cigarette smoking men (mean age: $44.29 \pm$ 11.66 years) and 100 healthy non-smoker men (mean age: $43.38 \pm 8.76$ years) were included in the study.

As mentioned, the universal vaccination of infants and children against diphtheria, tetanus and pertussis has been incorporated in the national immunization scheme in Iran since 1950 [11]. Accordingly all subjects born after this time (including subjects enrolled to this study) have received DTwP vaccine. Based-Line vaccination has been done by using 3 doses of vaccine at 2,4 , and 6 months of age with 3 booster reminder doses at age 18-24 months, 5-6 years and 18-24 years. There have been no other vaccination records regarding tetanus for participants.

The cigarette smokers were selected from subjects referring to the Pathobiological Laboratory of Rafsanjan University of Medical Sciences. Cigarette smoking, 
defined as smoking $\geq 1$ cigarettes per day for at least one year. Smoking status was assessed via questionnaire and all smokers recruited for the study were current smokers. A healthy non-smoking group (with similar socioeconomic status to the smoker group) was recruited among blood donors of Rafsanjan Blood Transfusion Center. The non-smokers were basically health, with no history of cigarette smoking or living as passive smokers. Subjects with disease such as history of recurrent infections, asthma, allergy and atopic diseases, any suspected immunological disorders and use of any drugs were all excluded from the study. Other exclusion criteria included any acute or chronic illnesses, malignancy, surgery and major trauma within 6 months prior to blood collection. Also the participants had not received any immunomodulating treatments during the 6 months prior to sampling. All participants had normal CBC, normal liver and normal renal function tests. Moreover, the blood lipids profile (including cholesterol and triglyceride) of all subjects were within the normal range.

This study was evaluated and approved by the Ethical Committee of Rafsanjan University of Medical Sciences and all of the participants gave written informed consent to take part in the study. Peripheral blood (2-4 milliliter) was collected from the subjects of 2 groups and the serum was separated and stored at $-20 \mathrm{C}$.

Serum levels of anti-TTA was measured by an enzyme-linked immunosorbentassay (ELISA) method by using commercial kits (IBL-Hamburg GmbH, Hamburg, Germany). Principally, the wells of ELISA plate are coated with tetanus toxin as antigen. Specific antibodies of the sample binding to the antigen coated wells are detected by a secondary enzyme conjugated antibody specific for human IgG. After the addition of substrate the intensity of the color is proportional to the amount of IgG-specific antibodies. Results of samples can be directly determined using the standard curve.

In the test procedure, after pipetting $100 \mu \mathrm{L}$ of each standard and diluted serum (1/100) into the respective wells, plates were incubated for $60 \mathrm{~min}$ at $25 \mathrm{C}$. At the end of the incubation period, plate strips were washed four times with $300 \mu \mathrm{L}$ washing buffer per well. Then, $100 \mu \mathrm{L}$ conjugate was added into each well. After the incubation period (for $30 \mathrm{~min}$ at $25 \mathrm{C}$ ), plate strips were washed as previously described. Thereafter, $100 \mu \mathrm{L}$ of Tetramethylbenzidine (TMB) substrate solution was added into each well and incubated for $20 \mathrm{~min}$ at $25 \mathrm{C}$ in dark. The substrate reaction was stopped by an addition of $50 \mu \mathrm{L}$ of sulfuric acid into each well. Optical density of each well was measured with a photometer at $450 \mathrm{~nm}$ within $60 \mathrm{~min}$ after pipetting of the stop solution.

Anti-TTA was measured by using standard samples with known concentrations of antiTTA expressed as IU/mL, provided by the manufacturer. According to manufacturer guideline, an antitoxin concentration $\geq 0.1$ $\mathrm{IU} / \mathrm{mL}$ was considered as protective level of antibody. Tetanus antitoxin levels less than $0.1 \mathrm{IU} / \mathrm{ml}$ were considered to denote susceptibility $[11,12]$. The sensitivity of ELISA kit was $0.004 \mathrm{IU} / \mathrm{ml}$.

Differences in antibody levels were analyzed using t-test and Chi-square test where appropriate and P-values of less than 0.05 were considered significant. All data were analyzed by SPSS software (version 15, Chicago, IL).

\section{Results}

The seroprotective rate of anti-TTA in healthy non-smoking group (99\%) was 
significantly higher than that observed in smoker group $(78 \%, \mathrm{P}<0.0001)$. The mean titer of anti-TTA in non-smoking group (5.32 $\pm 0.26 \mathrm{IU} / \mathrm{ml})$ was also significantly higher than that in smoker subjects $(1.03 \pm 0.16$ $\mathrm{IU} / \mathrm{ml} ; \mathrm{P}<0.0001)$.

Table 1: Serum concentrations of anti-tetanus toxin antibody (TTA) in cigarette smokers according to smoking duration

\begin{tabular}{|c|c|c|c|c|c|}
\hline Group & $\begin{array}{c}\text { Smoking } \\
\text { duration (years) }\end{array}$ & Number & $\begin{array}{c}\text { Protection rate } \\
\text { N }(\%)\end{array}$ & $\begin{array}{c}\text { The level of anti- } \\
\text { TTA (IU/mL) }\end{array}$ & $P$ value \\
\hline \multirow{3}{*}{ Smokers } & $\leq 10$ & 32 & $29(90.6 \%)$ & $1.98 \pm 0.41 \dagger$ & \multirow{3}{*}{$\begin{array}{l}*=0.037 \\
* *<0.001\end{array}$} \\
\hline & $>10$ & 68 & $49(72.1 \%)$ & $0.59 \pm 0.12$ & \\
\hline & Total & 100 & $78(78 \%)$ & $1.03 \pm 0.16$ & \\
\hline
\end{tabular}

$\uparrow$ The serum levels of anti-tetanus toxin antibody expressed as mean \pm SEM

* and ** represent the differences of protection rate and anti-tetanus antibody between two groups, respectively

The smokers were divided into two sub groups according to the smoking duration of the smokers. Thirty two subjects had been smokers for $\leq 10$ years and 68 persons had smoked for $>10$ years. The mean titer of antiTTA in individuals with smoking duration $>10$ years was significantly lower than smokers with smoking duration of $<10$ years $(0.59 \pm 0.12 \mathrm{IU} / \mathrm{ml}$ vs $1.98 \pm 0.41 \mathrm{IU} / \mathrm{ml}$; $\mathrm{P}<0.001)$. The seroprotection rate was also significantly lower in persons with smoking duration of $>10$ years in comparison to smokers with smoking duration of $<10$ years $(72.1 \%$ vs $90.6 \%$; $\mathrm{P}=0.037)$ (Table 1$)$.

Table 2: Serum concentrations of anti-tetanus toxin antibody in cigarette smokers according to the number of smoked cigarette per day

\begin{tabular}{cccccc}
\hline Group & $\begin{array}{c}\text { Number of } \\
\text { smoked cigarette } \\
\text { daily }\end{array}$ & Number & $\begin{array}{c}\text { Protection rate } \\
\mathbf{N}(\boldsymbol{\%})\end{array}$ & $\begin{array}{c}\text { anti-tetanus } \\
\text { toxin antibody } \\
(\mathbf{I U} / \mathbf{m L})\end{array}$ & P value \\
\hline \multirow{3}{*}{ Smokers } & $\leq 10$ & 37 & $32(86.5 \%)$ & $1.63 \pm 0.36 \dagger$ \\
\cline { 2 - 5 } & $>10$ & 63 & $46(73.0 \%)$ & $0.68 \pm 0.15$ \\
\cline { 2 - 5 }$* * 0.116$ \\
\hline
\end{tabular}

$\dagger$ The serum levels of anti-tetanus toxin antibody expressed as mean \pm SEM

* and ** represent the differences of protection rate and anti-tetanus antibody between two groups, respectively

According to the number of cigarettes smoked per day, the smokers were divided into two subgroups. Thirty seven subjects smoked $\leq 10$ cigarettes daily and 63 subjects smoked $>10$ cigarettes daily. The mean titer of anti-TTA in individuals with smoking $>10$ cigarettes daily was significantly lower in comparison with smokers with smoking $\leq 10$ cigarettes daily $(0.68 \pm 0.15 \mathrm{IU} / \mathrm{ml}$ vs $1.63 \pm$ $0.36 \mathrm{IU} / \mathrm{ml} ; \mathrm{P}<0.01)$. No significant difference was observed between persons smoking $>10$ cigarettes daily and persons smoking $\leq 10$ cigarettes daily with respect to seroprotection rate, although this parameter was found to be higher in individuals smoking $\leq 10$ cigarettes daily $(73.0 \%$ vs $86.5 \%$ ) (Table 2).

The distribution of subjects according to their serum levels of anti-TTA has been demonstrated in Figure 1. The rate of 
subjects with high serum levels of anti-TTA (>3 IU/mL) in non-smoking group was significantly higher in comparison to cigarettes smoking group $(75.00 \%$ vs $8.00 \%$; $\mathrm{P}<0.0001)$. On the other hand the rate of subjects with low serum levels of anti-TTA $(<1 \mathrm{IU} / \mathrm{mL})$ in cigarettes smoking group was significantly higher in comparison to nonsmoking group $(72.00 \%$ vs $7.00 \%$; $\mathrm{P}<0.0001$ ) (Figure 1).

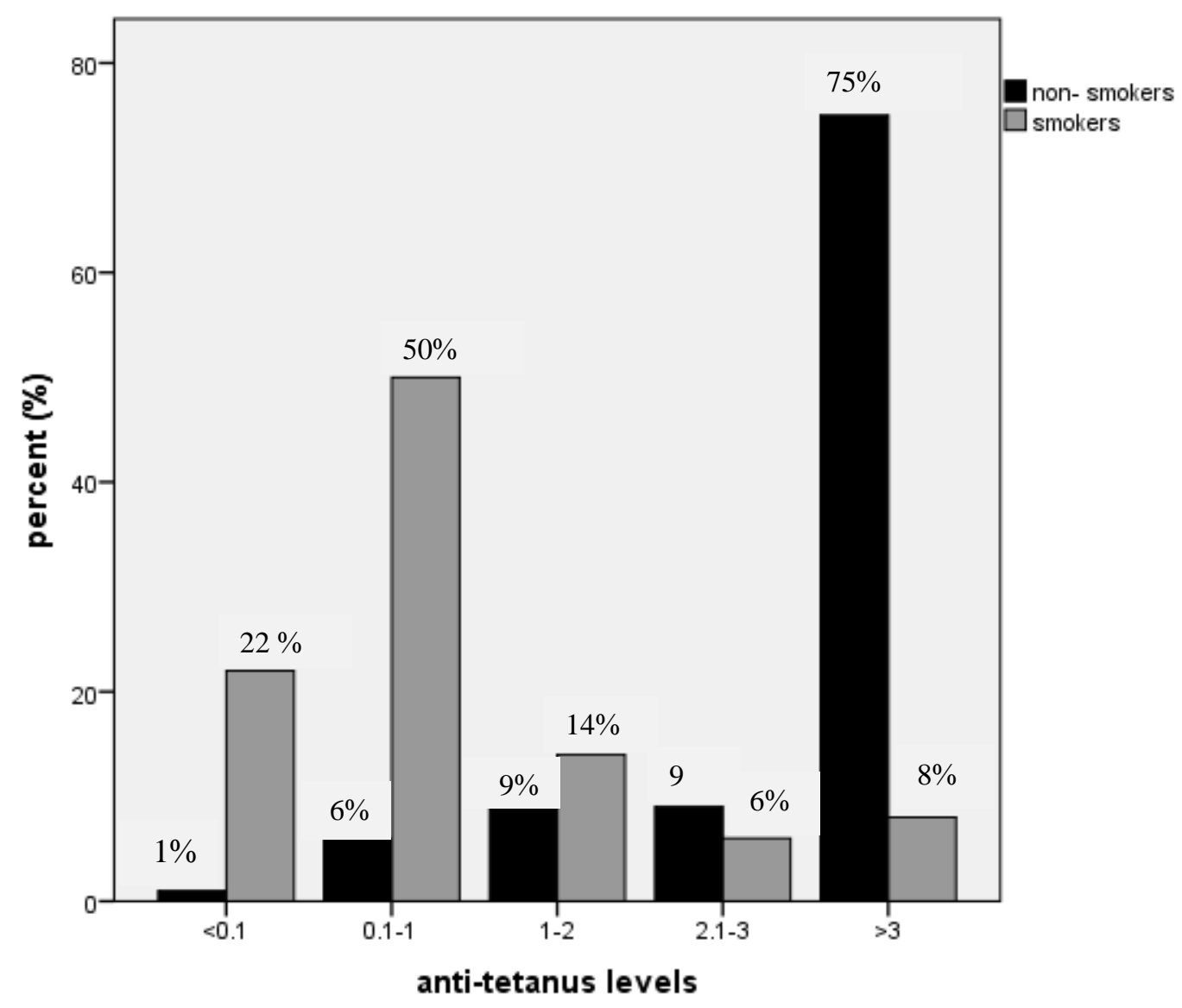

Figure 1: Distribution of subjects according to anti-tetanus toxin antibody in healthy and Smokers group

\section{Discussion}

The results of the present study showed that the seroprotective rate and the mean titer of anti-TTA were lower in cigarette smoking group as compared with non-smoker subjects. These findings represent that cigarette smoker subjects have a greater susceptibility to tetanus infection. There is no studies regarding the tetanus immunity in cigarette smoker subjects. In one study it was reported that in children with smoker parents the mean titer of anti-TTA was significantly lower in comparison with those who had non-smoker parents [18]. Moreover, it has been reported that the persistence of immunity to hepatitis B in cigarette smokers was lower than nonsmokers [19]. It has been recently reported that the immune response (within the nasal mucosa) to attenuated influenza virus vaccine were suppressed in smokers as compared to nonsmokers [20]. Furthermore, it has been reported that cigarette smokers are susceptible to infection and sepsis [21]. Some immunologic disorders have been shown in cigarette smokers. 
Several investigators have shown that longterm smoking significantly reduces serum levels of immunoglobulins (including $\mathrm{IgG}$, IgA and $\operatorname{IgM}$ ) in humans [22,23]. The suppressive effects of smoking on cell mediated immune responses have been also reported [24]. Moreover, cigarette smoking has been associated with depression of macrophages functions, decrease of $\mathrm{CD} 4+/ \mathrm{CD} 8+$ ratio, reduction of the numbers of dendritic cells, impairment of intracellular signaling pathways, and diminished production cytokines and chemokines $[25,26]$. In our previous study, it has been observed that cigarette smoke-exposed saliva samples have profound suppressive effects on both cellular and humoral immune responses in a mouse animal model [27]. Furthermore, we observed that cigarette smoke-exposed saliva have lethal effects on human lymphocytes [28].

It should be noted that vaccination is one of the most significant tools for inducing the prophylaxis against infection diseases. This prophylaxis is mediated via inducing of immunologic memory [29]. It has been demonstrated that cigarette smoke reduces the numbers of circulating memory $\mathrm{T}$ cells [30]. Accordingly, the lower levels of antiTTA in cigarette smokers may also be attributable in part to impairment of immunological memory in this subjects.

The results of the present study also demonstrated that both the titer of anti-TTA and the seroprotection rate were significantly lower in individuals with smoking duration of $>10$ years in comparison to smokers with smoking duration of $\leq 10$ years. Moreover, the titer of anti-TTA in individuals with cigarettes smoking of $>10$ daily was also significantly lower in comparison with smokers with cigarettes smoking of $\leq 10$ daily. The association of cigarette smoking intensity with several pathological outcomes such as increase in the risk of bladder cancer, higher dental caries, male infertility, increase in the risk of type 2 diabetes mellitus has also been reported in different studies [31,32]. Moreover, the association of cigarette smoking intensity with some inflammatory parameters such as higher levels of plasma complement $\mathrm{C} 3$, higher expression of inducible nitric oxide synthase has also been reported [33,34]. An association between cigarette smoking intensity and more susceptibility to human papillomavirus has been demonstrated too [35]. There is no study regarding the association of immune responses and cigarette smoking intensity. However, the results of the present study represent that the influence of cigarette smoking on the titer of anti-TTA mediated in a time- and dose-dependent manner. Thus, there is a negative association between the smoking burden and the titer of anti-TTA.

According to serum levels of anti-TTA we have arbitrary classified the subjects to several subgroups. In non-smoking group $75 \%$ of subjects have the anti-TTA >3 $\mathrm{IU} / \mathrm{mL}$ whereas only $8 \%$ of smoker subjects have the anti-TTA $>3 \mathrm{IU} / \mathrm{mL}$. On other hand, the proportion of subjects with low anti-TTA $(<1 \mathrm{IU} / \mathrm{mL})$ was higher in smoker groups in comparison to the non-smoking group. This classification can be use for designing of the re-vaccination program. According to manufacturer guideline, for individuals with antitoxin level $<0.1 \mathrm{IU} / \mathrm{ml}$ (no protection), vaccine should be administered. Individuals with antitoxin level $0.1-1 \mathrm{IU} / \mathrm{ml}$ should be controlled after 1-2 years. Individuals with antitoxin level 1.1-5.0 IU/ml should be controlled after 2-4 years. Individuals with antitoxin level $>5.0 \mathrm{IU} / \mathrm{ml}$ should be controlled after 8 years. Similar guideline has been presented for re-vaccination by Centers for Disease Control and Prevention [36, 37]. The CDC's Advisory Committee on 
Immunization Practices recommended that all smokers aged 19-64 years be vaccinated with the pneumococcal polysaccharide vaccine $[38,39]$. The incorporation of other vaccines such as tetanus vaccine in a smokers vaccination program need more consideration in future studies.

\section{Conclusion}

The results of the present study showed lower levels of anti-TTA in cigarette smokers. Moreover, a reverse association was also observed between the titer of antiTTA and smoking burden.

\section{Acknowledgements}

This work was financially supported by a grant from Rafsanjan University of Medical Sciences, Rafsanjan, Iran.

\section{Conflict of interest: Non declared}

\section{References}

1. Lenney W, Enderby B. "Blowing in the wind": a review of teenage smoking. Arch Dis Child 2008; 93(1):72-5.

2. Domagala-Kulawik J. Effects of cigarette smoke on the lung and systemic immunity. J Physiol Pharmacol 2008; 59 Suppl 6:19-34.

3. Arnson Y, Shoenfeld Y, Amital H. Effects of tobacco smoke on immunity, inflammation and autoimmunity. J Autoimmun 2010; 34(3):J258-65.

4. Maryono S, Guntur A, Suharti C. Serum complement 3 (C3) and complement 4 (C4) level in febrile neutropenia patients at Dr. Kariadi Hospital, Semarang and Dr. Moewardi Hospital, Surakarta. Acta Med Indones 2008; 40(1):14-8.

5. Wraith DC, Nicholson LB. The adaptive immune system in diseases of the central nervous system. J Clin Invest 2012; 122(4):1172-9.

6. Huttunen R, Heikkinen $\mathrm{T}$, Syrjanen $\mathrm{J}$. Smoking and the outcome of infection. J Intern Med 2011; 269(3):258-69.

7. Hymowitz N. Smoking and cancer: a review of public health and clinical implications. $\mathrm{J}$ Natl Med Assoc 2011; 103(8):695-700.

8. Ataro P, Mushatt D, Ahsan S. Tetanus: a review. South Med J 2011; 104(8):613-7.

9. Koromath FS, Sumarmi, Hermawan AG. Infectious disease pattern and serum albumin levels in elderly people hospitalized at Dr. Moewardi Hospital Surakarta during 2004. Acta Med Indones 2008; 40(3):114-6.

10. Reed DB, Westneat SC. Exposure risks and tetanus immunization status in farmers ages 50 and over. South Med J 2009; 102(3):2515.

11. Zarei S, Jeddi-Tehrani M, Akhondi MM, Zeraati H, Pourheidari F, Ostadkarampour M, et al. Primary immunization with a triple diphtheria-tetanus-whole cell pertussis vaccine in Iranian infants: an analysis of antibody response. Iran $\mathbf{J}$ Allergy Asthma Immunol 2009; 8(2):85-93.

12. Zarei S, Jeddi-Tehrani M, Akhondi MM, Zeraati H, Kheirkhah T, Ghazanfari M, et al. Immunogenicity of a triple diphtheriatetanus-whole cell pertussis vaccine in Iranian preschool children. Iran J Immunol 2007; 4(2):101-9.

13. Choi JH, Choo EJ, Huh A, Choi SM, Eom JS, Lee JS, et al. Immunogenicity and safety of diphtheria-tetanus vaccine in adults. $\mathbf{J}$ Korean Med Sci 2010; 25(12):1727-32.

14. Simen-Kapeu A, Kataja V, Yliskoski M, Syrjänen K, Dillner $\mathrm{J}$, Koskela $\mathrm{P}$, et al. Smoking impairs human papillomavirus (HPV) type 16 and 18 capsids antibody response following natural HPV infection. Scand J Infect Dis 2008; 40(9):745-51.

15. Koff RS. Immunogenicity of hepatitis B vaccines: implications of immune memory. Vaccine 2002; 20(31-32):3695-701.

16. Kean J. The effects of smoking on the wound healing process. J Wound Care 2010; 19(1):5-8.

17. Thomsen SF, Sorensen LT. Smoking and skin disease. Skin Therapy Lett 2010; 15(6):4-7.

18. Baynam G, Khoo SK, Rowe J, Zhang G, Laing I, Hayden C, et al. Parental smoking impairs vaccine responses in children with 
atopic genotypes. J Allergy Clin Immunol 2007; 119(2):366-74.

19. Horowitz MM, Ershler WB, McKinney WP, Battiola RJ. Duration of immunity after hepatitis B vaccination: efficacy of low-dose booster vaccine. Ann Intern Med 1988; 108(2):185-9.

20. Horvath KM, Brighton LE, Herbst M, Noah TL, Jaspers I. Live attenuated influenza virus (LAIV) induces different mucosal $\mathrm{T}$ cell function in nonsmokers and smokers. Clin Immunol 2012; 142(3):232-6.

21. Koh GC, Peacock SJ, van der Poll T, Wiersinga WJ. The impact of diabetes on the pathogenesis of sepsis. Eur J Clin Microbiol Infect Dis 2012; 31(4):379-88.

22. Aral M, Ekerbicer HC, Celik M, Ciragil P, Gul M. Comparison of effects of smoking and smokeless tobacco "Maras powder" use on humoral immune system parameters. Mediators Inflamm 2006; 2006(3):85019.

23. Sopori M. Effects of cigarette smoke on the immune system. Nat Rev Immunol 2002; 2(5):372-7.

24. Edwards D. Immunological effects of tobacco smoking in "healthy" smokers. COPD 2009; 6(1):48-58.

25. Tymkiw KD, Thunell DH, Johnson GK, Joly S, Burnell KK, Cavanaugh JE, et al. Influence of smoking on gingival crevicular fluid cytokines in severe chronic periodontitis. J Clin Periodontol 2011; 38(3):219-28.

26. Birrell MA, Wong S, Catley MC, Belvisi MG. Impact of tobacco-smoke on key signaling pathways in the innate immune response in lung macrophages. J Cell Physiol 2008; 214(1):27-37.

27. Jafarzadeh A, Bakhshi H, Rezayati MT, Nemati M. Cigarette smoke-exposed saliva suppresses cellular and humoral immune responses in an animal model. J Pak Med Assoc 2009; 59(11):760-3.

28. Nozad-Mojaver Y, Mirzaee M, Jafarzadeh A. Synergistic effects of cigarette smoke and saliva. Med Oral Patol Oral Cir Bucal 2009; 14(5):E217-21.

29. Castellino F, Galli G, Del Giudice G, Rappuoli R. Generating memory with vaccination. Eur J Immunol 2009; 39(8):2100-5.

30. Vardavas CI, Plada M, Tzatzarakis M,
Marcos A, Warnberg J, Gomez-Martinez S, et al. Passive smoking alters circulating naive/memory lymphocyte T-cell subpopulations in children. Pediatr Allergy Immunol 2010; 21(8):1171-8.

31. Pramono LA, Setiati S, Soewondo P, Subekti I, Adisasmita A, Kodim N, et al. Prevalence and predictors of undiagnosed diabetes mellitus in Indonesia. Acta Med Indones 2010; 42(4):216-23.

32. Campus G, Cagetti MG, Senna A, Blasi G, Mascolo A, Demarchi P, et al. Does smoking increase risk for caries? a cross-sectional study in an Italian military academy. Caries Res 2011; 45(1):40-6.

33. Coelho C, Julio C, Silva G, Neves A. Tobacco and male infertility: a retrospective study in infertile couples. Acta Med Port 2009; 22(6):753-8.

34. Nagaya T, Yoshida H, Takahashi H, Kawai M. Heavy smoking raises risk for type 2 diabetes mellitus in obese men; but, light smoking reduces the risk in lean men: a follow-up study in Japan. Ann Epidemiol 2008; 18(2):113-8.

35. Meric A, Ozucer B, Gedikli O, Yildirim Y, Korkut AY, Kahya V, et al. Impact of Smoking on p65 Nuclear Factor kB, p38 Mitogen-Activated Protein Kinase, and Inducible Nitric Oxide Synthase Expression Levels in Oral Mucosa. J Craniofac Surg 2012; 23(4):970-3.

36. van Greevenbroek MM, Jacobs M, van der Kallen CJ, Blaak EE, Jansen EH, Schalkwijk $\mathrm{CG}$ et al. Human plasma complement $\mathrm{C} 3$ is independently associated with coronary heart disease, but only in heavy smokers (the CODAM study). Int J Cardiol 2012; 154(2):158-62.

37. Vaccarella S, Herrero R, Snijders PJ, Dai M, Thomas JO, Hieu NT et al. Smoking and human papillomavirus infection: pooled analysis of the International Agency for Research on Cancer HPV Prevalence Surveys. Int J Epidemiol 2008; 37(3):536-46.

38. Centers for Disease Control and Prevention (CDC). Neonatal tetanus--Montana, 1998. MMWR Morb Mortal Wkly Rep 1998; 47(43):928-30.

39. Kuehn BM. CDC panel recommends vaccine for smokers; reviews HPV safety data. JAMA 2008; 300(23):2713-4. 